\title{
Машиностроение. Металлообработка
}

УДК 621.914.5:62.231.3

DOI: $10.17277 /$ vestnik.2015.03.pp.504-512

\section{ПОСТРОЕНИЕ ВНУТРЕННИХ (ФОРМООБРАЗУЮЩИХ) ЦЕПЕЙ МЕТАЛЛОРЕЖУЩИХ СТАНКОВ НА ОСНОВЕ ШАГОВОГО ГИДРОПРИВОДА}

\author{
В. А. Ванин, А. Н. Колодин, И. В. Облицов
}

Кафедра «Компьютерно-интегрированные системы в машиностроении», ФГБОУ ВПО «ТГТУ»; oblitsovivan@mail.ru

Ключевые слова: внутренние (формообразующие) цепи; гидравлические связи; гидравлический шаговый привод; металлорежущие станки.

Аннотация: Рассмотрена возможность применения гидравлических связей на основе шагового гидропривода для построения внутренних (формообразующих) цепей металлорежущих станков со сложными движениями. Показано формообразование различного технологического назначения в целях повышения точности, снижения металлоемкости, создания рациональной конструкции кинематических цепей станков с использованием агрегатно-модульного принципа.

\section{Введение}

При создании новой модели металлорежущего станка или модернизации существующей модели актуальной становится задача проектирования и построения внутренних (формообразующих) цепей станков, представляющих собой часть общей структуры, рациональной по функциональной точности, многозвенности и металлоемкости.

Структура кинематических цепей в значительной степени определяет конструктивную сложность станка, методы его настройки, оказывает существенное влияние на точность (кинематическую и геометрическую) и жесткость для осуществления взаимосвязанных формообразующих и координатных перемещений.

Одним из основных показателей качества металлорежущих станков является точность, которая представляет собой результат следующих факторов:

- правильного выбора общей компоновки конструкции станка и его отдельных узлов, в особенности внутренних (формообразующих) цепей;

- высокой точности изготовления и сборки;

- жесткости технологической системы.

Известные традиционные методы построения внутренних (формообразующих) цепей металлорежущих станков на основе механических связей и повышения их точности достигли определенного предельного уровня и практически не имеют резервов повышения точности, особенно в имеющих сложные разветвленные многозвенные переналаживаемые цепи значительной протяженности, которые должны обеспечить жесткую функциональную связь для создания взаимосвязанных формообразующих движений заготовки и инструмента. 
Для осуществления в станке исполнительного движения между заготовкой и инструментом необходимо создать кинематическую связь между исполнительными звеньями и их связь с источником движения. Такие связи в станках в большинстве своем осуществляются с помощью механических звеньев как в цепях главного движения и подач, так и во внутренних (формообразующих) цепях построенных индивидуализированных конструкций разного технологического назначения со сложными движениями формообразования различного типа и разных типоразмеров [1].

\section{Характеристика формообразующих цепей металлорежущиущих станков, построенных из механических звеньев}

Кинематические внутренние (формообразующие) цепи с механическими звеньями обеспечивают точные передаточные отношения между заготовкой и инструментом и не требуют дополнительных поднастроек в процессе работы.

На кинематическую точность внутренних (формообразующих) цепей, составленных из механических звеньев (валы, зубчатые и иные передачи, муфты и т.п.), влияют геометрическая неточность элементов и их взаимного расположения, обусловленная погрешностями обработки и сборки.

Существенное влияние на точность кинематических цепей оказывают температурные деформации и крутильная жесткость.

При сложном пространственном расположении рабочих органов станка узел заготовки и узел инструмента, - при большом числе промежуточных подвижных звеньев цепи и при значительном расстоянии между подвижными рабочими органами жесткие кинематические цепи, составленные из механических звеньев, становятся громоздкими, что приводит к усложнению конструкции цепи и станка, а также снижению точности функционально связанных перемещений исполнительных органов, увеличению металлоемкости.

Одним из возможных, практически реализуемых, способов повышения точности внутренних (формообразующих) цепей металлорежущих станков и сохранения ее в процессе эксплуатации является сокращение их протяженности и применение взамен механических цепей гидравлических связей в виде высокоточного дискретного шагового гидравлического привода, обеспечивающего высокую точность согласования угловых и линейных перемещений и возможность прямого непосредственного соединения исполнительного шагового гидродвигателя с нагрузкой, исключая при этом промежуточные механические передачи, редукторы, коробки подач [2].

\section{Применение гидравлического шагового привода для построения внутренних (формообразующих) цепей металлорежущих станков}

Структурно шаговый гидропривод представляет собой гидромеханическую систему из трех конструктивно и функционально завершенных агрегатов (блоков): управляющего (коммутирующего) устройства, выполненного в виде генератора гидравлических импульсов различного конструктивного исполнения, источника рабочей жидкости (насосная установка), и исполнительного силового гидравлического шагового двигателя (ГШД), выходной вал которого отрабатывает дискретные управляющие сигналы с высокой точностью и большим усилением по мощности. Работа ГШД зависит от числа и последовательности поступления управляющих импульсов, формирование и распределение которых осуществляется с помощью различного типа коммутирующих устройств, при этом каждому управляющему импульсу соответствует определенный фиксированный угол поворота выходного вала ГШД, соединенного с исполнительными органами стан- 
ка - заготовкой и инструментом. Скорость вращения и суммарный угол поворота выходного вала ГШД пропорциональны соответственно частоте и числу управляющих импульсов. При использовании шагового гидропривода во внутренних (формообразующих) цепях станков передаточное отношение между исполнительными органами гидравлической связи зависит от соотношения частот управляющих импульсов, формируемых управляющим устройством (генератором гидравлических импульсов) и подаваемых к исполнительным шаговым двигателям привода заготовки и инструмента.

Передаточное отношение внутренней (формообразующей) цепи, выполненной в виде гидравлической связи на основе шагового гидропривода, связывающей в определенной зависимости движение заготовки и инструмента, зависит от соотношения частот гидравлических импульсов, подаваемых к ГШД, осуществляющим движение заготовки и инструмента.

Используя свойства частотного регулирования скорости исполнительных ГШД, представляется возможным применить гидравлические связи на основе шагового гидропривода для построения внутренних (формообразующих) цепей станков, требующих точного взаимосвязанного формообразующего движения заготовки и инструмента, имеющих сложное пространственное расположение рабочих органов при значительном расстоянии между подвижными органами станка, сложные разветвленные многозвенные переналаживаемые механические цепи значительной протяженности, где требуется осуществить необходимые относительные взаимосвязанные формообразующие движения инструмента и обрабатываемой заготовки, где наличие тяжело-нагруженных протяженных силовых кинематических цепей, подверженных значительным механическим и температурным деформациям и износу, требует применения громоздких механических устройств.

Ниже рассмотрены структурные схемы металлорежущих станков различного технологического назначения, формообразующие кинематические цепи которых построены в виде гидравлических связей на основе шагового гидропривода с различными схемами коммутации рабочей жидкости.

\section{Реализация построения гидравлических внутренних (формообразующих) цепей металлорежущих станков на основе шагового гидропривода}

На рисунке 1 приведена структурная схема токарно-затыловочного станка с гидравлическими формообразующими связями для обработки конических резьбовых гребенчатых фрез с винтовыми структурными канавками и системой управления от блоков гидрораспределителей, построенной на базе двухкромочного золотника с торцовым распределением рабочей жидкости [3-4].

Станок включает в себя заготовку 19, которая совершает вращательное движение от электродвигателя Д через звено настройки $i_{v}$ и инструмент 16 , взаимодействующий с заготовкой по цепи затылования (деления).

Движение деления (затылования), связывающее между собой вращения заготовки 19 и вращение кулачка затылования 15, от которого получает возвратнопоступательное движение верхняя каретка 23 с инструментом 16, осуществляется от шагового гидродвигателя 12, управляемого генератором гидравлических импульсов, золотниковая втулка которого получает вращение от зубчатого колеса, жестко закрепленного на шпинделе изделия.

Продольное перемещение инструмента 16 связано с вращением заготовки винторезной цепью и осуществляется от шагового гидродвигателя 25 , кинематически связанного с продольным суппортом 28, посредством ходового винта 11 продольной подачи.

506 ISSN 0136-5835. Вестник ТГТУ. 2015. Том 21. № 3. Transactions TSTU. 


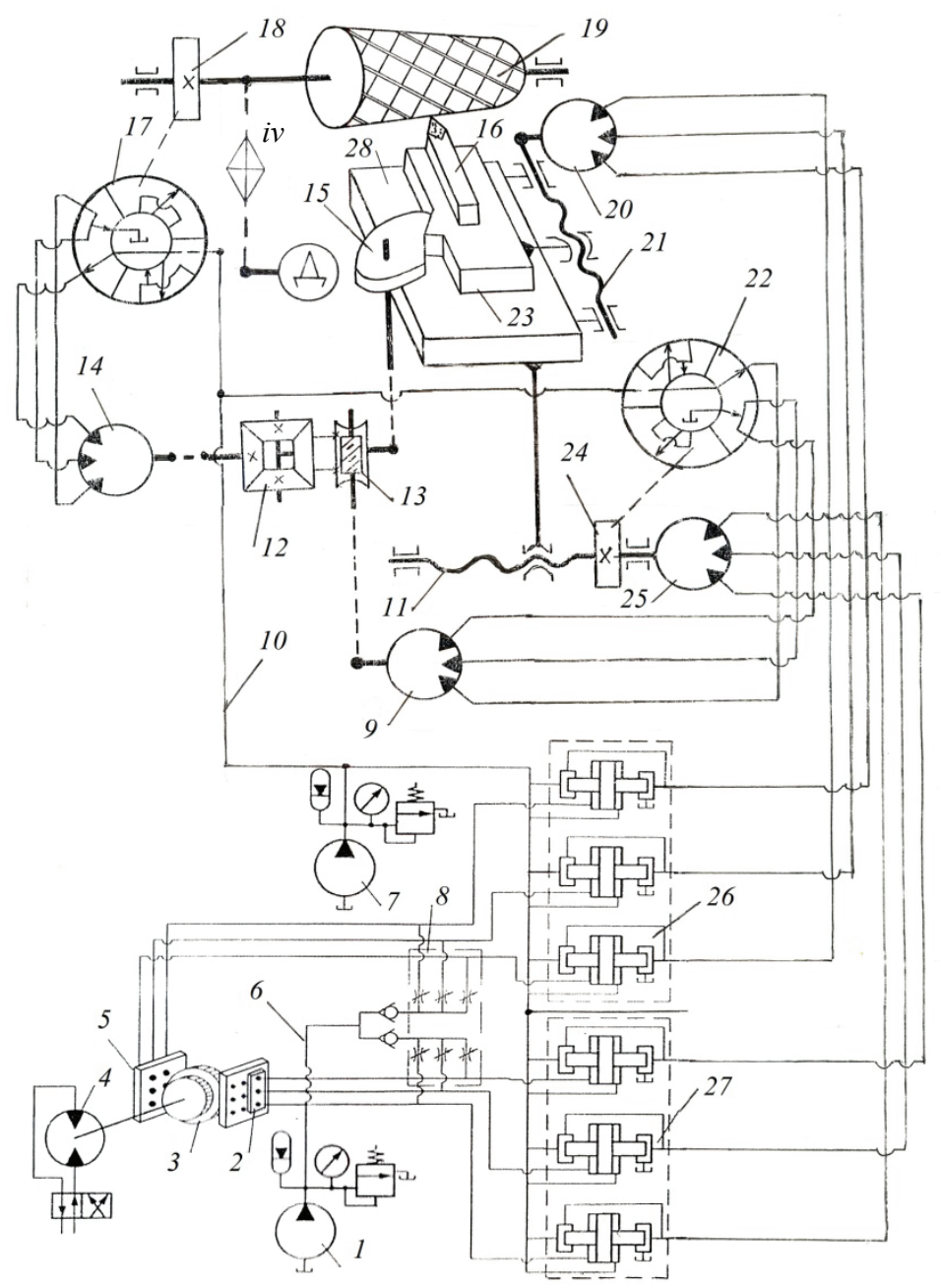

Рис. 1. Структурная схема токарно-затыловочного станка с гидравлическими формообразующими связями для обработки конических резьбовых гребенчатых фрез с винтовыми структурными канавками

Поперечное перемещение верхней каретки 23 суппорта с инструментом 16 , необходимое для воспроизведения наклонной образующей конической поверхности, осуществляется гидравлической связью, включающей в себя шаговый гидродвигатель 20, кинематически связанный посредством ходового винта 21 поперечной подачи верхних салазок 23 с инструментом.

Дифференциальное движение, необходимое при затыловании конических резьбовых изделий с винтовыми стружечными канавками и обеспечивающее добавочный поворот кулачку затылования 15 , от которого совершается возвратнопоступательное движение инструмента при продольном перемещении суппорта 28 , осуществляется шаговым гидродвигателем 18 , кинематически связанным с кулачком затылования через суммирующий механизм 12 в виде дифференциала с коническими колесами посредством червячной передачи 13.

Управление шаговыми гидродвигателями 20 и 25 приводов продольного перемещения продольного суппорта 28 и поперечного перемещения верхних салазок 23 с инструментом осуществляется от блоков гидрораспределителей 26 и 27 с торцовым распределением рабочей жидкости. 
Настройка гидравлической связи на требуемое передаточное отношение производится генератором гидравлических импульсов 3 , который представляет собой устройство, выполненное в виде набора кодирующих дисков, закрепленных на общей оси и получающих вращение от отдельного гидромотора 4. Рабочая жидкость для получения управляющих импульсов для гидрораспределителей с торцовым распределителем рабочей жидкости поступает от насосной установки 1 через блок управляемых дросселей 8 по каналу 6.

Передаточное отношение между исполнительными органами гидравлической связи - шаговыми гидродвигателями 20 и 25 приводов продольного перемещения продольного суппорта 28 и поперечного перемещения верхней каретки суппорта 23 зависит от соотношения частот гидравлических импульсов, формируемых генератором и распределяемых по рабочим камерам исполнительных шаговых гидродвигателей, и определяется числом импульсов, подаваемых за один оборот блока кодирующих дисков генератора.

Изменение передаточного отношения цепи обката (деления) производится перемещением ползушек 2 на корпусе генератора гидравлических импульсов относительно периферии кодирующего диска с различным числом выступов, осуществляя при этом коммутацию потоков рабочей жидкости по силовым каналам, в зависимости от того, какая щель управляющих каналов перекрыта в данный момент времени выступом вращающегося диска генератора импульсов [5-7].

Давление питания на вход каждого из гидрораспределителей подается через регулируемый дроссель блока дросселей 8 от насосной установки 1 , а затем, в зависимости от положения торцовых гидрораспределителей, по одному из каналов поступает в рабочие камеры шаговых гидродвигателей 20 и 25 приводов продольного перемещения продольного суппорта 28 и поперечного перемещения верхней каретки суппорта 23.

Генератор гидравлических импульсов формирует гидравлические импульсы давления и распределяет их по рабочим камерам шаговых гидродвигателей путем периодического в определенной последовательности открытия и закрытия рабочих щелей. Наружная поверхность каждого из кодирующих дисков выполнена таким образом, что его выступы либо перекрывают сопло, либо оставляют его открытым, при этом один выступ диска может перекрывать только лишь одну щель, то есть скважность между выступом и впадиной кодирующего диска выполняется в соотношении

$$
t_{\text {щ }}=t_{\mathrm{B}}\left(m \pm \frac{1}{n}\right)
$$

где $n$ - число щелей, соответствующее числу каналов шагового гидродвигателя; $t_{\mathrm{B}}-$ шаг выступов кодирующего диска; $m$ - целое число, выбирается из условия размещения и подсоединения рабочих щелей к гидролиниям.

Рабочие щели в корпусе генератора гидравлических импульсов располагаются с шагом $t_{\mathrm{B}}$.

При таком расположении щелей относительно выступов вращающегося кодирующего диска через две оставшиеся незакрытыми щели рабочая жидкость поступает на слив, а одна щель всегда перекрывается выступом диска. Поверхность кодирующего диска и рабочая щель (сопло) образуют управляемый дроссель, а пространство между соплом и постоянным дросселем образует междроссельную камеру, давление в которой зависит от величины зазора между соплом и поверхностью выступов кодирующего диска.

В момент, когда выступ вращающегося диска генератора гидравлических импульсов находится напротив рабочей щели и перекрывает ее, происходит скачкообразное повышение управляющего давления в междроссельной камере, в ре- 
зультате чего происходит переключение гидрораспределителя. При отсутствии управляющего сигнала (импульса давления) распределитель находится в левом положении под действием давления питания. Рабочая жидкость для получения управляющих импульсов для гидрораспределителей с торцовым распределителем рабочей жидкости поступает от насосной установки 1 через блок управляемых дросселей 8. Генератор гидравлических импульсов обеспечивает постоянное для данной настройки отношение частот гидравлических импульсов давления, а, следовательно, частот вращения выходных валов гидравлических шаговых двигателей заготовки и инструмента.

Коммутация потоков рабочей жидкости по силовым и рабочим камерам шаговых гидродвигателей зависит от того, какая щель управляющих каналов перекрыта в данный момент выступом вращающегося кодирующего диска генератора гидравлических импульсов.

На рисунке 2 представлена структурная схема резьбонарезного станка с гидравлическими формообразующими связями для обработки цилиндрических винтовых поверхностей переменного шага с модифицированным механизмом приращения шага [8].

Станок содержит рабочий орган, состоящий из суппорта 13 , с размещенным на нем режущим инструментом 11, а также рабочий орган (шпиндель), несущий заготовку 10, на которой нарезается винтовая поверхность переменного шага.

Резьбонарезной станок для нарезания цилиндрических винтовых поверхностей переменного шага включает в себя: кинематическую цепь начального шага, связывающую между собой вращение шпинделя и продольное перемещение продольного суппорта с инструментом; цепь изменения шага, связанную с цепью начального шага посредством суммирующего механизма, выполненного в виде дифференциала с коническими колесами и задающего закон изменения шага, выполненного в виде коррекционной линейки с реечной зубчатой передачей.

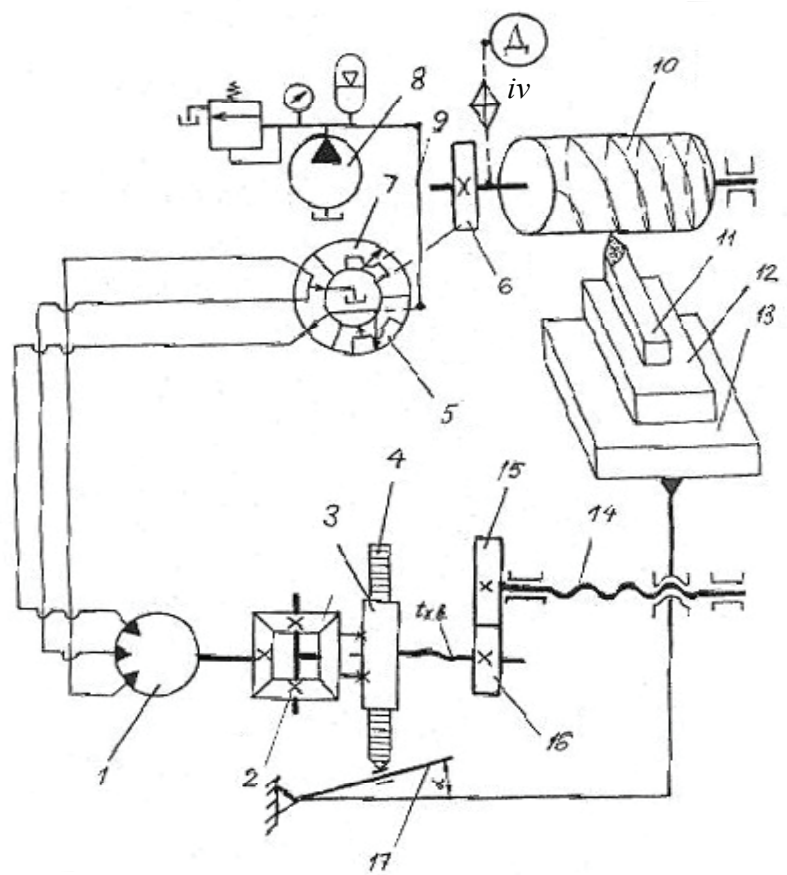

Рис. 2. Структурная схема резьбонарезного станка с гидравлическими формообразующими связями для обработки цилиндрических винтовых поверхностей переменного шага 
Формообразование винтовой поверхности переменного шага осуществляется в результате равномерного вращения заготовки, установленной в центрах передней и задней бабок и неравномерного поступательного перемещения суппорта с инструментом. Переменный шаг винтовой линии червяка образуется в результате того, что суппорту сообщается одновременно два движения: одно с постоянной скоростью от ходового винта и другое с переменной скоростью от механизма приращения шага, выполненного в виде коррекционной линейки с реечной передачей.

Вращение заготовки 10 осуществляется от электродвигателя Д через звено настройки $i v$. Продольное перемещение суппорта 13 с инструментом 11 (цепь начального шага винтовой поверхности) осуществляется от шагового гидродвигателя 1 , кинематически связанного с суппортом 13 посредством ходового винта 14 и управляемого генератором гидравлических импульсов 5 , золотниковая втулка с рабочими щелями которого получает вращение от приводного зубчатого колеса 6, жестко закрепленного на шпинделя заготовки 10.

Дополнительное перемещение суппорта 13 с инструментом, необходимое для получения величины приращения шага винтовой поверхности при продольном перемещении суппорта, осуществляется от коррекционной линейки 17 , установленной под углом к линии центров станка. При продольном перемещении суппорта 13 одновременно будет перемещаться в поперечном направлении к линии центров станка зубчатая рейка 4 , шарнирно связанная с установленной под углом коррекционной линейкой 17 и поворачивать реечное зубчатое колесо 3 , связанное с суммирующем механизмом 2 в виде дифференциала с коническими колесами. Рабочая жидкость к генератору гидравлических импульсов поступает от насосной установки 8 по трубопроводу 9.

\section{Заключение}

Использование гидравлических связей на основе шагового гидравлического привода обеспечивает построение внутренних (формообразующих) цепей металлорежущих станков по модульному принципу. Это позволит построить различные по характеристикам и технологическим возможностям внутренние кинематические цепи станков разных назначений и типов на основе ограниченной номенклатуры функционально и конструктивно завершенных блоков (модулей). Гидравлические связи во внутренних цепях станков, построенные по модульному принципы, обладают положительными качествами, отличными от традиционных механических связей, а именно:

1) обеспечивается конструктивная однородность внутренних (формообразующих) кинематических цепей станков различного технологического назначения и разных типоразмеров;

2) унификация элементов привода исключает конструктивное и размерное многообразие кинематических внутренних цепей, предназначенных для выполнения однотипных задач;

3) обеспечивается рациональное построение кинематических схем с наименьшим числом составляющих механических элементов, возможность прямого непосредственного соединения исполнительного силового шагового двигателя с исполнительными звеньями цепи - заготовкой и инструментом без применения промежуточных коробок подач, редуктора, промежуточных звеньев, что значительно упрощает построение кинематических станков;

4) уменьшается металлоемкость и масса станка. 


\title{
Список литературы
}

1. Федотенок, Л. А. Кинематическая структура металлорежущих станков / Л. А. Федотенок. - М. : Машиностроение, 1970. - 403 с.

2. Колодин, А. Н. Затыловочные станки с гидравлическими формообразующими связями : монография / А. Н. Колодин, В. А. Ванин, А. А. Родина. Deutschland : LAP Lambert Academic Publishing, 2015. - 169 c.

3. Ванин, В. А. Станки с гидравлическими внутренними (формообразующими) связями на основе шагового гидропривода для обработки винтовых поверхностей / В. А. Ванин, А. Н. Колодин // Инженер. журн. с приложениями. 2012. - № 7(184). - C. 30 - 35 .

4. Металлорежущие станки с гидравлическими связями на основе шагового гидропривода во внутренних (формообразующих) цепях / В. А. Ванин, [и др.] // Вестн. Тамб. гос. техн. ун-та. - 2013. - Т. 19, № 1. - С. 167 - 176.

5. Применение шагового гидропривода для построения формообразующих цепей металлорежущих станков со сложными движениями формообразования / В. А. Ванин [и др.] // Вопр. соврем. науки и практики. Университет им. В. И. Вернадского. 2014. - № 1(50). - С. $250-259$.

6. Родина, А. А. Синтез и оптимизация кинематической структуры станков со сложными движениями формообразования на основе гидравлических связей / А. А. Родина, И. В. Облицов, А. С. Поляков // Проблемы техногенной безопасности и устойчивого развития : сб. науч. тр. молодых ученых, аспирантов и студентов, 2015 / Тамб. гос. техн. ун-т. - 2015. - Вып. VI. - С. 77 - 81.

7. Vanin, V. A. Modular Design Based on Hydraulic Step Drives for Internal Kinematic Chains in Metal-Cutting Machines / V. A. Vanin, A. N. Kolodin // Russian Engineering Research. - 2010. - No. 30(12). - P. 1248 - 1251.

8. Vanin, V. A. Application of Hydraulic Step Drives in Metal-Cutting Machine Tools / V. A. Vanin, A. N. Kolodin // Russian Engineering Research. - 2010. No. 30(5). - P. $446-450$.

9. Пат. 2147488 Российская Федерация, МПК 7В23В5/42. Токарно-затыловочный станок с гидравлическими связями для затылования червячных фрез / Ванин В.А. ; заявитель и патентообладатель Тамб. гос. техн. ун-т. - № 98111265/02 ; заявл. 09.06.1998, Бюл. № 11.5 с.

\section{Building Internal (Formative) Chains of Machine Tools Based on Hydraulic Drive Stepper}

\author{
V. A. Vanin, A. N. Kolodin, I. V. Oblitsov \\ Department «Computer-Integrated Systems in Mechanical Engineering», \\ «TSTU»; oblitsovivan@mail.ru
}

Keywords: hydraulic connections; hydraulic drive stepper; internal (formative) chain; metal-cutting machines.

Abstract: The possibility of applying the hydraulic transmission on the basis of hydraulic drive stepper to build internal (formative) chains of machine tools with complex movements is studied. The authors show the possibility of using internal formative chains to increase accuracy, reduce metal consumption, and create a sound design of machines with kinematic chains using aggregate-modular principle.

\section{References}

1. Fedotenok L.A. Kinematicheskaya struktura metallorezhushchikh stankov (The kinematic structure of machine tools), M.: Mashinostroenie, 1970, $403 \mathrm{p}$.

2. Kolodin A.N., Vanin V.A., Rodina A.A. Zatylovochnye stanki s gidravlicheskimi formoobrazuyushchimi svyazyami. Monografiya (Backing machines with 
hydraulic formative connections: monograph), Deutschland: LAP Lambert Academic Publishing, 2015, 169 p.

3. Vanin V.A., Kolodin A.N. Inzhenernyi zhurnal s prilozheniyami, 2012, no. 7 (184), pp. 30-35.

4. Vanin V.A., Kolodin A.N., Do M.Z., Damap M.M. Transactions of the Tambov State Technical University, 2013, Vol. 19, no. 1, pp. 167-176.

5. Vanin V.A., Kolodin A.N., Averin A.S., Khramova N.A. Voprosy sovremennoi nauki i praktiki. Universitet im. V.I. Vernadskogo, 2014, no. 1(50), pp. 250-259.

6. Rodina A.A., Oblitsov I.V., Polyakov A.S. Problemy tekhnogennoi bezopasnosti i ustoichivogo razvitiya: sbornik nauchnykh trudov molodykh uchenykh, aspirantov $i$ studentov (Problems of technological safety and sustainable development: collection of scientific works of young scientists and students), 2015 Tambov, Vol. VI., pp. 77-81.

7. Vanin V.A., Kolodin A.N. Russian Engineering Research, 2010, 30 (12), pp 1248-1251.

8. Vanin V.A., Kolodin A.N. Russian Engineering Research, 2010, 30 (5), pp 446-450.

9. Vanin V.A., Tambov State Technical University, Tokarno-zatylovochnyi stanok s gidravlicheskimi svyazyami dlya zatylovaniya chervyachnykh frez (Turning Backing machine with hydraulic binders for zatylovaniya hobs) Russian Federation, 2000, Pat. 2147488.

\section{Aufbau der inneren (formbildenden) Ketten der spanabhebenden Werkzeugmaschinen aufgrund des Schritthydraulikantriebes}

Zusammenfassung: Es ist die Möglichkeit der Anwendung der hydraulischen Verbindungen aufgrund des Schritthydraulikantriebes für die Bildung der inneren (formbildenden) Ketten der spanabhebenden Werkzeugmaschinen mit den komplizierten Bewegungen betrachtet. Es ist die Formbildung der verschiedenen technologischen Zweckbestimmung für die Erhöhung der Exaktheit, die Senkung des Materialeinsatzes, die Schaffung der Rationalkonstruktion der kinematischen Ketten der Werkzeuge mit der Benutzung des Aggregatmodulprinzipes gezeigt.

\section{Construction des chaînes intérieures (constituant une forme) des tours à métaux à la base du fil hydraulique pas à pas}

Résumé: Est examinée la possibilité de l'application des liens hydrauliques à la base du fil hydraulique pas à pas pour la construction des chaînes intérieures (constituant une forme) des tours à métaux aux mouvements complexes. Est montrée la constitution des formes de différente destination technologique dans les buts de l'augmentation de la précision, la diminution de la teneur en métal, la création de la construction rationnelle des chaînes cinématiques des machines-outils avec l'utilisation du principe agrégative modulaire.

Авторы: Ванин Василий Агафонович - доктор технических наук, профессор кафедры «Компьютерно-интегрированые системы в машиностроении»; Колодин Андрей Николаевич - ассистент кафедры «Компьютерно-интегрированые системы в машиностроении»; Облицов Иван Владимирович - магистрант кафедры «Компьютерно-интегрированые системы в машиностроении», ФГБОУ ВПО «ТГТУ».

Рецензент: Муромцев Дмитрий Юрьевич - доктор технических наук, профессор, проректор по научно-инновационной деятельности, ФГБОУ ВПО «ГТТУ». 